Steven Fox, MD

Department of Critical Care Medicine,

Respiratory Institute, Cleveland Clinic
Siddharth Dugar, MD

Department of Critical Care Medicine,

Respiratory Institute, Cleveland Clinic

\title{
Point-of-care ultrasound and COVID-19
}

\section{Posted April 18, 2020}

\begin{abstract}
Point-of-care ultrasound has an important role in the management of patients with COVID-19 infection. Because the utility of each application varies by setting, individual institutions should consider how they can best use ultrasound within their specific environments. In general, procedural guidance and focused echocardiography are high yield. Lung ultrasound has the potential to aid the diagnosis and management of patients with COVID-19 infection. Lower extremity point-of-care ultrasound for deep vein thrombosis may help guide decision making regarding anticoagulation or undifferentiated shock. It is of the utmost priority that ultrasound not spread infection, so point-of-care ultrasound must be used only when clinically indicated. Institutions should have protocols for machine disinfection.
\end{abstract}

\section{BACKGROUND}

The highly infectious nature of the SARS-CoV-2 virus via respiratory droplets can lead to contamination of medical and radiologic devices during use. The concern for nosocomial spread of the virus among healthcare workers and other hospitalized patients has led many societies and medical centers to recommend appropriately limiting exposure and imaging. ${ }^{1,2}$

Point-of-care ultrasound is increasingly being used to diagnose, monitor, and manage patients in emergency departments and in those admitted to inpatient services. In patients with COVID-19 infection it is an excellent tool for comprehensive examination given that ultrasound is already commonly used in patient care, handheld ultrasound devices are easy to clean, and the nature of the virus is critical and dynamic.

In this Curbside Consult, we present typical lung ultrasound findings in patients with COVID-19 infection and discuss other uses of point-of-care ultrasound

The statements and opinions expressed in COVID-19 Curbside Consults are based on experience and the available literature as of the date posted. While we try to regularly update this content, any offered recommendations cannot be substituted for the clinical judgment of clinicians caring for individual patients.

doi:10.3949/ccjm.87a.ccc019 in their care. We also highlight key points about the disinfection of ultrasound machines and introduce a protocol that minimizes the time needed to assess infected patients for deep vein thrombosis as well as lung and cardiac abnormalities.

\section{TYPICAL FINDINGS OF COVID-19}

\section{Description of findings}

Typical lung patterns seen on ultrasonography in patients with COVID-19 infection include the following (Figure 1$)^{3}$ :

- Pleural irregularity and thickening (early finding)

- Subpleural consolidations

- B lines may be seen, often derived from areas of irregular pleura; these become more confluent and diffuse as the disease progresses.

- Spared areas (a pattern of normal lung interspersed between focal B lines) are usually present early in the disease

- Nonlobar and translobar consolidation with air bronchograms

- Small localized pleural effusions may be seen, but moderate or large basilar pleural effusions are rare.

\section{Findings are nonspecific}

These lung ultrasound findings are not specific to COVID-19 and are seen in other pneumonias (viral and bacterial) and inflammatory pneumonitis. Severe cases of COVID-19 are similar in appearance to acute respiratory distress syndrome from other etiologies. The findings differ from cardiogenic pulmonary edema, which is frequently characterized by bilateral lower-lobe-predominant B lines with smooth pleura. Alternatively, lack of lung ultrasound findings consistent with COVID-19 infection in acute respiratory failure may suggest an alternative etiology.

\section{POTENTIAL APPLICATIONS OF LUNG ULTRASOUND}

\section{Increased diagnostic sensitivity}

The importance of correctly identifying patients with COVID-19 is imperative for management and isolation because a false-negative COVID-19 test result 

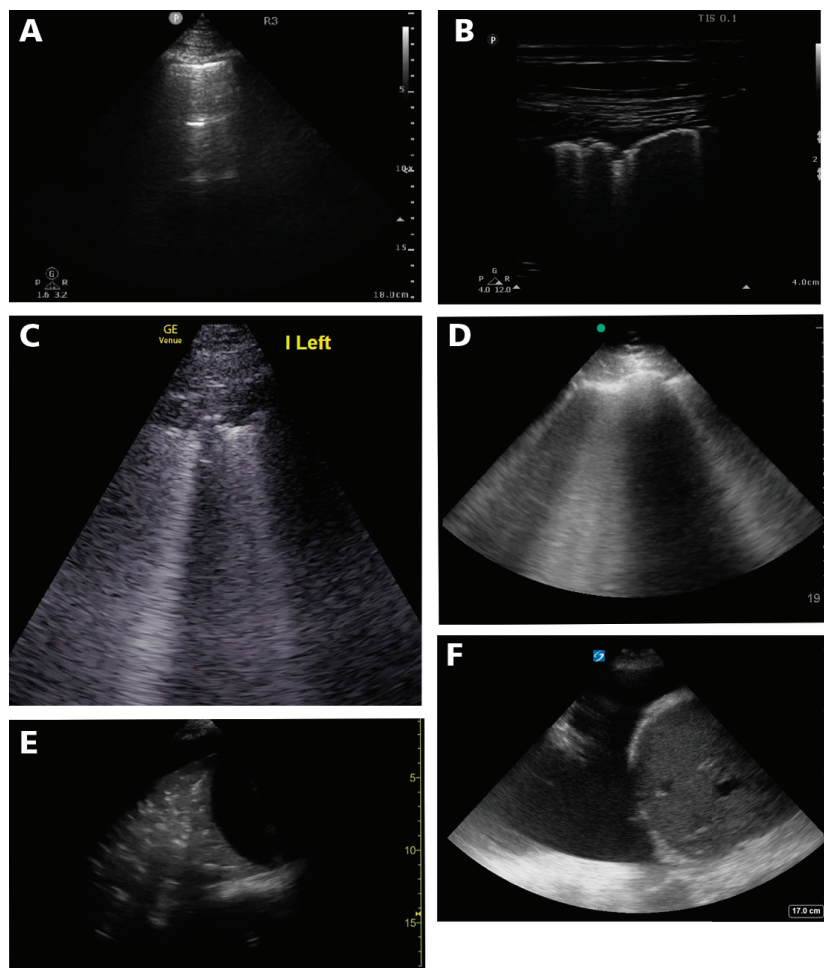

Figure 1. Relevant lung ultrasound findings in patients with COVID-19 infection. A: An "A pattern" as shown here may be present in multiple lung zones in patients with COVID-19; this may be referred to as a "spared area." B: Pleural irregularity and B lines; in early COVID-19 infection, B lines appear from areas of pleural irregularity or subpleural consolidation. C: Subpleural consolidation, as characterized by an irregular, typically hypoechoic area just beneath the pleura, often with B lines deep or adjacent to it. D: B lines become progressively more frequent and confluent as the extent of interstitial edema progresses; this appearance is similar to that of acute respiratory distress syndrome of any cause. E: Large basilar consolidation, with air bronchograms, and a subpulmonic effusion. F: Large pleural effusion; this is not typical of COVID-19 infection in isolation.

may lead to a false sense of security and increase the risk of exposure. Chest computed tomography has been used in several settings as part of the rule-out process due to its high sensitivity $(98 \%$, vs $70 \%$ for reverse transcription polymerase chain reaction testing). ${ }^{4}$ However, this approach is associated with high resource use and risk of caregiver exposure.

One study reported a strong concordance between chest computed tomography and lung ultrasound performed simultaneously in patients presenting with flu-like symptoms. ${ }^{5}$ The authors of that study suggested using lung ultrasound as an alternative to chest computed tomography for early diagnosis of COVID19 infection.

Lung ultrasound has been used in Italy during the COVID-19 outbreak to facilitate appropriate resource utilization, including testing. ${ }^{6}$ The broad application faces challenges including concern for false-negative test results, operator variability, clinician time to perform the ultrasound study, and risk of caregiver exposure.

\section{Triage and prognostication}

The use of lung ultrasound to triage patients to an appropriate level of care based on the observed abnormality has been suggested. ${ }^{6}$ Patients with COVID-19 infection who do not have any abnormalities on lung ultrasound and do not require supplemental oxygen can be observed at home. On the other hand, patients with gross lung ultrasound abnormalities or signs that these abnormalities are worsening may require a higher level of care in the intensive care unit as research suggests that there is an association between more prominent lung ultrasound abnormalities and clinical deterioration. ${ }^{7}$ Thus, lung ultrasound has a potential role to play in triage in some settings. However, it cannot be broadly recommended at this time due to a lack of data.

\section{Characterization of disease}

Lobar consolidations may raise suspicion for a superimposed bacterial process. ${ }^{6}$ Patients with wellaerated anterior lung may derive greater benefit from proning. ${ }^{8}$ Lung ultrasound can estimate lung recruitment with positive end-expiratory pressure in acute respiratory distress syndrome. ${ }^{9}$ However, use of lung ultrasound for ventilator titration cannot be broadly recommended in patients with COVID-19 infection due to limited added benefit and the need for frequent examinations, which increases the risk of exposure and disease spread.

Mild to moderate cases of COVID-19 infection have a similar pattern to nonlobar pneumonias (atypical, interstitial, or bronchopneumonia) (Table 1). Severe cases of COVID-19 have more dense or confluent B lines and have a pattern similar to acute respiratory distress syndrome. Cardiogenic pulmonary edema has a distinct pattern distinguished by smooth pleura, intact sliding, and the absence of subpleural consolidations and spared areas. Lobar pneumonia has a distinct pattern distinguished by large lobar consolidations with air bronchograms. Key distinguishing features are shown in bold.

\section{OTHER APPLICATIONS OF POINT-OF-CARE ULTRASOUND}

\section{Focused echocardiography}

The mortality rate in critically ill patients with COVID-19 infection has been suggested to be $>20 \%$, with a high incidence of shock. ${ }^{10,11}$ The shock syn- 
TABLE 1

Sonographic findings in pulmonary edema, COVID-19 viral pneumonia, and bacterial pneumonia

\begin{tabular}{|c|c|c|c|c|c|c|}
\hline & \multicolumn{2}{|c|}{ Pulmonary Edema } & \multicolumn{2}{|c|}{ COVID-19 (viral pneumonia) } & \multicolumn{2}{|c|}{ Bacterial Pneumonia } \\
\hline & $\begin{array}{l}\text { Cardiogenic } \\
\text { pulmonary } \\
\text { edema }\end{array}$ & $\begin{array}{l}\text { Non-cardiogenic } \\
\text { pulmonary } \\
\text { edema (ARDS) }\end{array}$ & $\begin{array}{l}\text { Severe lung } \\
\text { involvement }\end{array}$ & $\begin{array}{l}\text { Mild-moderate } \\
\text { lung } \\
\text { involvement }\end{array}$ & $\begin{array}{l}\text { Nontobar } \\
\text { pneumonias }\end{array}$ & $\begin{array}{l}\text { Lobar } \\
\text { Pneumonia }\end{array}$ \\
\hline$B$ lines & $\begin{array}{l}\text { Diffuse } \\
\text { Dependent } \\
\text { distribution }\end{array}$ & $\begin{array}{l}\text { Diffuse } \\
\text { Maybe confuent }\end{array}$ & $\begin{array}{l}\text { Diffuse } \\
\text { May be } \\
\text { confluent }\end{array}$ & $\begin{array}{l}\text { Focal, derived } \\
\text { from areas of } \\
\text { irregular pleura }\end{array}$ & $\begin{array}{l}\text { Variable } \\
\text { (Focal, multibcal, } \\
\text { or difuse) }\end{array}$ & $\begin{array}{l}\text { Adjacentto } \\
\text { consolidations }\end{array}$ \\
\hline Spared areas & A bsent & Present & Present & Present & Present & Present \\
\hline Pleura & Smooth & Irregular & Irregular & Irregular & Irregular & Irregular \\
\hline Pleural sliding & Normal & Reduced & Reduced & Reduced & Reduced & Reduced \\
\hline $\begin{array}{l}\text { Subpleural } \\
\text { consolidations }\end{array}$ & Not seen* & Present & Present & Present & Maybe present & Maybe present \\
\hline $\begin{array}{l}\text { Large } \\
\text { consolidations }\end{array}$ & Not seen" & $\begin{array}{l}\text { Present, } \\
\text { typically } \\
\text { dependent }\end{array}$ & $\begin{array}{l}\text { Present, } \\
\text { typically } \\
\text { dependent }\end{array}$ & Not seen & Notseen & $\begin{array}{l}\text { Lobar, with air } \\
\text { bronchograms }\end{array}$ \\
\hline $\begin{array}{l}\text { Moderate-large } \\
\text { pleural effusion }\end{array}$ & Often present & $\begin{array}{l}\text { Infequent. Small } \\
\text { pleural effusions } \\
\text { maybe present }\end{array}$ & $\begin{array}{l}\text { Infrequert. Small } \\
\text { pleural effusions } \\
\text { maybe present }\end{array}$ & Not seen" & Notseen & Maybe present. \\
\hline Laterality & Bilateral & Bilateral & Bilateral & Bilateral & Unilateral & Unilateral \\
\hline
\end{tabular}

*If seen, a superimposed process should be considered.

drome in this group can be distributive, from sepsis or vasoplegia (eg, due to sedation). ${ }^{12}$ The presence of elevated troponin in the setting of pre-existing cardiovascular disease is associated with significant mortality $(69.44 \%)$. In one study, the overall mortality in critically ill patients with elevated troponin levels was $59 \%$ compared with $8.8 \%$ in patients with no elevation. ${ }^{13}$ Acute cardiac injury may occur due to demand ischemia, acute fulminant myocarditis, worsening of pre-existing myocardial disease, acute coronary syndrome due to plaque rupture, or acute right ventricular failure (due to thromboembolism or pulmonary vasoconstriction from acute lung injury and high ventilator pressures). ${ }^{14}$

The varied causes of shock necessitate close monitoring of cardiovascular function. ${ }^{11}$ Focused echocardiography should be performed in patients who are in a state of shock to assess left ventricular systolic function and right ventricular size and function. It should also be used in these patients for basic assessment of cardiac valve function and regional wall-motion abnormalities. Noninvasive cardiac output estimation using left ventricular outflow tract velocity time integral may further guide the evaluation of shock. The need for conservative fluid management in patient with acute respiratory distress syndrome necessitates assessment of dynamic volume responsiveness and volume tolerance before fluid administration. ${ }^{15}$

Focused echocardiography may influence volume management, ventilator management (for right ventricle protection), assessment of the need for proneposition ventilation, and titration of inotropes and vasopressors. ${ }^{16-18}$ Point-of-care echocardiography performed by the bedside clinician may obviate the need for comprehensive echocardiography, reducing resource use and risk of infection spread. ${ }^{2}$

\section{Deep vein thrombosis}

COVID-19 infection is associated with a hyperinflammatory state with a high incidence $(20 \%)$ of deep vein thrombosis. ${ }^{19}$ In one study, anticoagulant therapy was associated with a better prognosis in severe 


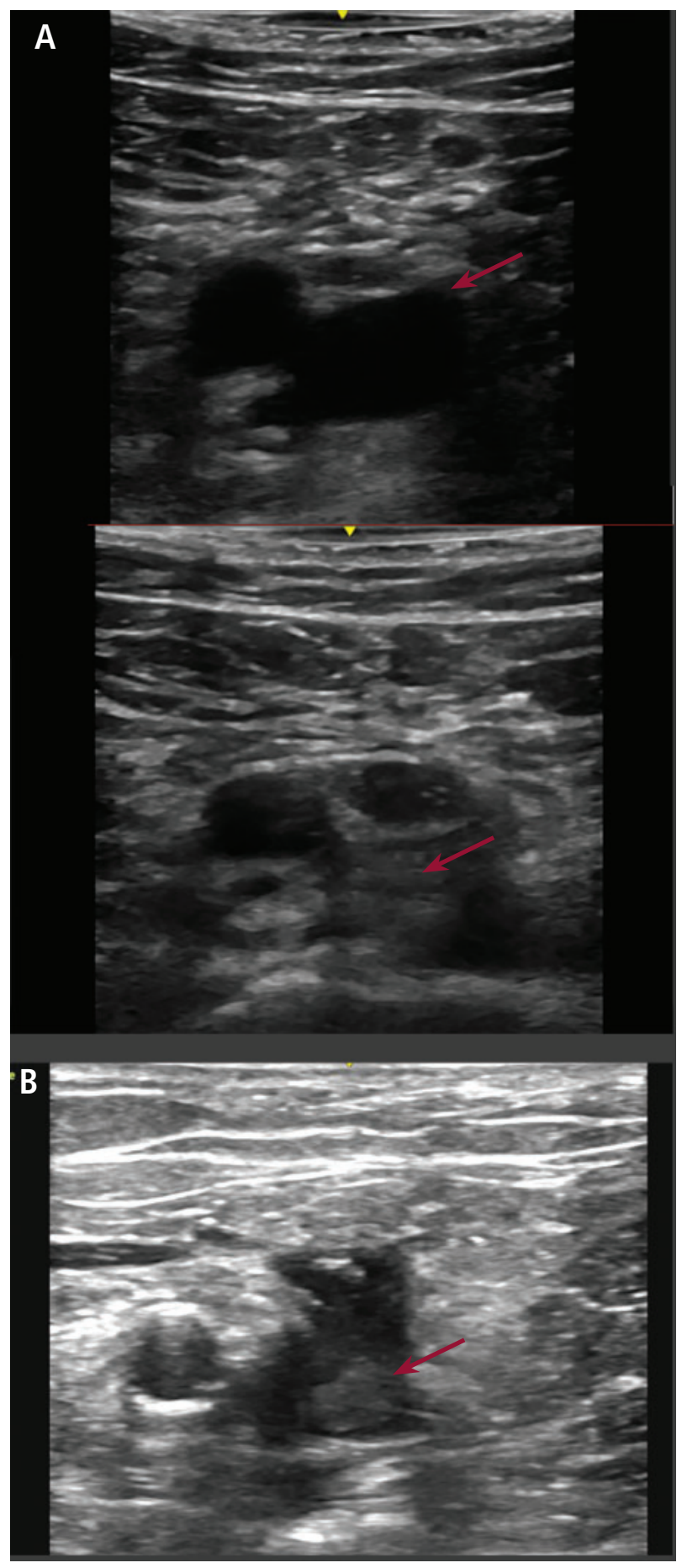

Figure 2. A: Venous compression study at the common femoral vein. The vein appears circular and anechoic in the upper image. It collapses completely with compression in the lower image. This maneuver rules out clot at this site. The arrow indicates the common femoral vein. B: Intra-luminal echogenic material is seen in the vein at the femoral saphenous junction. The arrow indicates the echogenic clot in the vein. When an obvious thrombus is visible, compression should not be performed due to the theoretical risk of provoking clot embolization.
COVID-19 infection. ${ }^{20}$ The sensitivity of limited bedside lower-extremity ultrasound for the diagnosis of deep vein thrombosis (Figure 2) ranges from $84 \%$ to $97 \%$ and has a specificity of $>95 \% .21,22$

A "2-point DVT" scan using gray-scale imaging to evaluate vein compression at the common femoral and popliteal veins has been recommended for ease of use but may miss $5.5 \%$ of DVT cases. ${ }^{23} \mathrm{~A}$ "2-region" technique may be more appropriate and is recommended. ${ }^{24}$ This involves compression of an area of $1 \mathrm{~cm}$ to $2 \mathrm{~cm}$ proximal and distal to the greater saphenous vein junction with the common femoral vein extending to the confluence of the deep and superficial femoral vein, and of a second area behind the knee extending from the proximal popliteal vein to the confluence of the calf vein. In case the clinical suspicion for a DVT remains high despite a negative study result, a comprehensive ultrasound study performed by a vascular technician should be obtained.

\section{Procedural}

Multiple professional society guidelines recommend using ultrasound for central venous catheter and arterial catheter placement to improve the safety and success rate of the procedure. ${ }^{25}$ Use of point-of-care ultrasound for procedural guidance is strongly recommended, even in facilities that do not use it diagnostically in patients with COVID-19 infection. Figure 3 provides guidance on the use of ultrasound machines for patients with confirmed or suspected cases of COVID-19 infection.

\section{DISINFECTION PROTOCOL}

It is of the utmost priority that ultrasound not spread COVID-19 infection. Several guidelines have been developed for disinfection of ultrasound machines. ${ }^{26,27}$

A few key points are described here:

- Each institution should have a cleaning protocol for machines prior to use on COVID-19 patients.

- Point-of-care ultrasound examinations should only be performed when necessary and should be consolidated during a single visit as much as possible.

- An ultrasound machine should be dedicated to patients with suspected or confirmed COVID-19 infection as much as possible. Handheld machines may be easier to clean and their use should be promoted. A probe cover should be used. No extra supplies should be on the machine. The power cord should be removed from the machine if possible.

- The machine should be cleaned twice between patients: once with personal protective equipment on, and once with clean gloves after doffing the 


\begin{tabular}{|l|l|l|}
\hline $\begin{array}{l}\text { JUDICIOUS USE } \\
\begin{array}{l}\text { Use ultrasound only when necessary } \\
\text { (procedures, critical diagnostics) }\end{array}\end{array}$ & SCANNING CAREFFULLY & $\begin{array}{l}\text { CLEANING } \\
\text { Use a probe cover }\end{array}$ \\
$\begin{array}{l}\text { Ultrasound is not needed to diagnose } \\
\text { COVID }\end{array}$ & $\begin{array}{l}\text { Have exam loaded on machine before } \\
\text { entering room } \\
\text { inside room }\end{array}$ & $\begin{array}{l}\text { Clean twice: once inside room before } \\
\text { removing PPE, and again outside room } \\
\text { with clean gloves }\end{array}$ \\
$\begin{array}{l}\text { Use POCUS to minimize use of other } \\
\text { tests (TTE, chest CT) }\end{array}$ & $\begin{array}{l}\text { Do not plug in machine } \\
\text { (if charge adequate) }\end{array}$ & $\begin{array}{l}\text { Use grey-top PDI wipes } \\
\text { (Sani-cloth AF3) }\end{array}$ \\
$\begin{array}{l}\text { Use the dedicated machine for all } \\
\text { confirmed and suspected cases }\end{array}$ & $\begin{array}{l}\text { One hand to scan, other to touch } \\
\text { machine }\end{array}$ & $\begin{array}{l}\text { Wipe entire machine and allow to dry } \\
\text { at least } 3 \text { minutes }\end{array}$ \\
\hline
\end{tabular}

Figure 3. Guidance for use of ultrasound machines for patients with confirmed or suspected COVID-19.

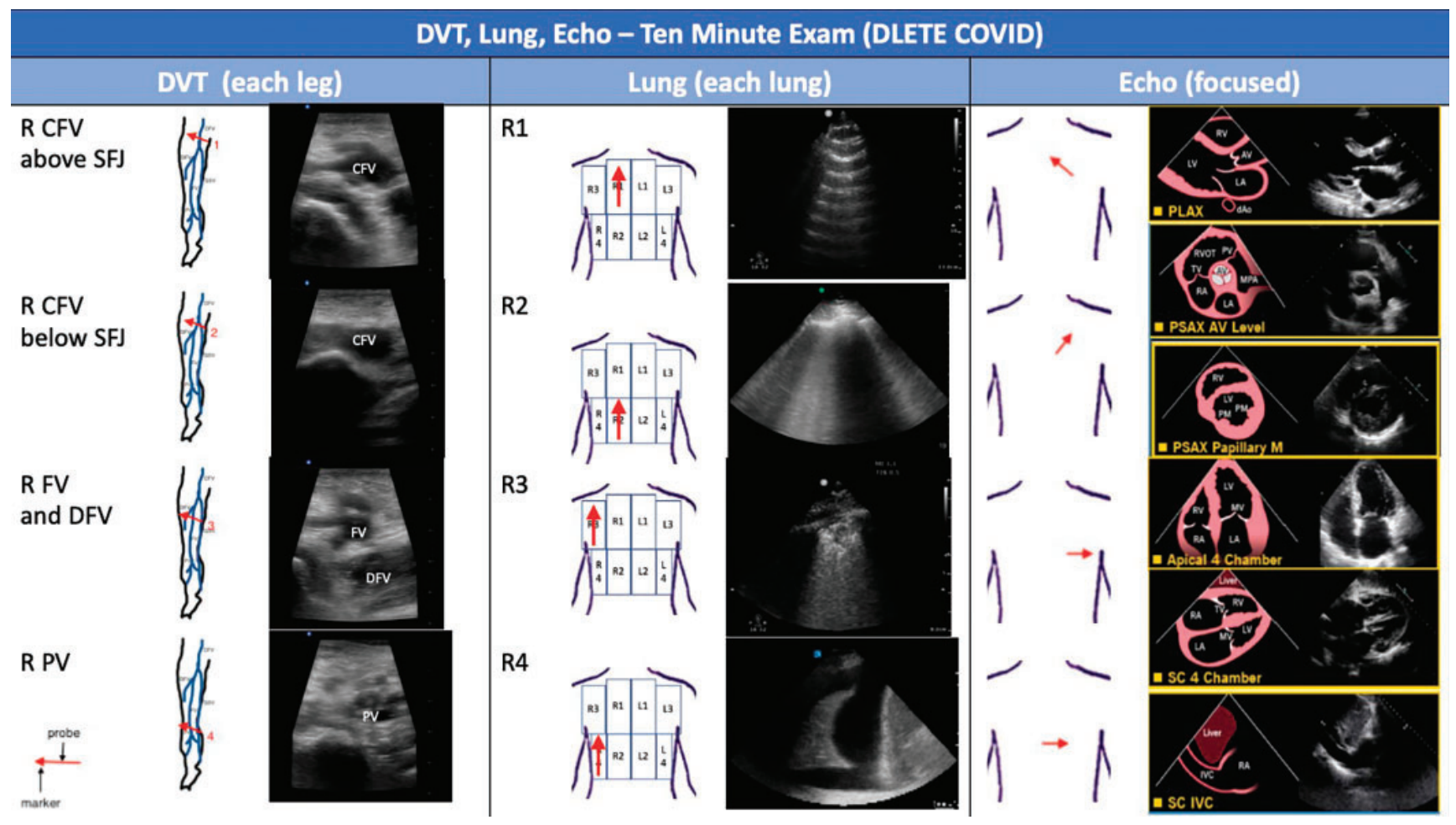

Figure 4. The DLETE COVID-19 point-of-care ultrasound protocol. The examination for deep vein thrombosis is performed with the linear probe, and lung and cardiac exams are performed with the phased array probe.

protective equipment. The cleaning wipe should be a type approved for emerging pathogens by the US Environmental Protection Agency.
Even in patients without particular concern for COVID-19, point-of-care ultrasound should be used judiciously during a pandemic to limit patient contact 
and fomite transmission from patients with undiscovered viral shedding. Educational scanning should be limited. Extra attention should be paid to rigorous cleaning of ultrasound machines between patients.

\section{DOING THIS IN PRACTICE: THE DLETE PROTOCOL}

A major challenge, particularly amidst increasing staffing demands, is the time required to perform the point-of-care ultrasound exam. A protocol (Figure 4) called DLETE (DVT, lung, echo ten-minute exam ) has been developed that shows caregivers how to asses COVID-19-positive patients for deep vein thrombosis as well as for lung and heart abnormalities in 10 minutes. The protocol may be utilized on admission to the intensive care unit and combined with physical exam. The full study or individual components may be repeated later in the event of hemodynamic decompensation.

\section{SUMMARY}

Point-of-care ultrasound has an important role in the management of patients with COVID-19 infection. Because the utility of each application varies by setting, individual institutions should consider how they can best use ultrasound within their specific environments. In general, procedural guidance and focused echocardiography are high yield. Lung ultrasound has the potential to aid the diagnosis and management of patients with COVID-19 infection. Lower extremity point-of-care ultrasound for deep vein thrombosis may help guide decision making regarding anticoagulation or undifferentiated shock. It is of the utmost priority that ultrasound not spread infection, so point-of-care ultrasound must be used only when clinically indicated. Institutions should have protocols for machine disinfection.

\section{REFERENCES}

1. American College of Radiology. ACR Recommendations for the use of Chest Radiography and Computed Tomography (CT) for Suspected COVID-19 Infection. https://www.acr.org/Advocacy-andEconomics/ACR-Position-Statements/Recommendations-for-ChestRadiography-and-CT-for-Suspected-COVID19-Infection. Accessed April 17, 2020.

2. Johri AM, Galen B, Kirkpatrick JN, Lanspa M, Mulvagh S, Thamman R. ASE Statement on Point-of-Care Ultrasound (POCUS) During the 2019 Novel Coronavirus Pandemic [published online April 15, 2020]. J Am Soc Echocardiogr 2020. https://doi.org/10.1016/j. echo.2020.04.017

3. Peng QY, Wang XT, Zhang LN; Chinese Critical Care Ultrasound Study Group (CCUSG). Findings of lung ultrasonography of novel corona virus pneumonia during the 2019-2020 epidemic. Intensive Care Med 2020; Mar 12. doi:10.1007/s00134-020-05996-6

4. Fang $\mathbf{Y}$, Zhang $\mathrm{H}$, Xie J, et al. Sensitivity of chest CT for COVID19: comparison to RT-PCR. Radiology 2020; Feb 19. doi:10.1148/ radiol.2020200432

5. Poggiali E, Dacrema A, Bastoni D, et al. Can lung US help criti- cal care clinicians in the early diagnosis of novel coronavirus (COVID-19) pneumonia? Radiology 2020; Mar 13. doi:10.1148/ radiol.2020200847

6. Soldati G, Smargiassi A, Inchingolo R, et al. Is there a role for lung ultrasound during the COVID-19 pandemic? J Ultrasound Med 2020; Mar 20. doi:10.1002/jum.15284

7. Bouhemad B, Mongodi S, Via G, Rouquette I. Ultrasound for "lung monitoring" of ventilated patients. Anesthesiology 2015; 122(2):437-447. doi:10.1097/ALN.0000000000000558

8. Prat G, Guinard S, Bizien N, et al. Can lung ultrasonography predict prone positioning response in acute respiratory distress syndrome patients? J Crit Care 2016; 32:36-41. doi:10.1016/j.jcrc.2015.12.015

9. Bouhemad B, Brisson H, Le-Guen M, Arbelot C, Lu Q, Rouby JJ. Bedside ultrasound assessment of positive end-expiratory pressure-induced lung recruitment. Am J Respir Crit Care Med 2011; 183(3):341-347. doi:10.1164/rccm.201003-03690C

10. Grasselli G, Zangrillo A, Zanella A, et al. Baseline characteristics and outcomes of 1591 patients infected with SARS-CoV-2 admitted to ICUs of the Lombardy Region, Italy. JAMA 2020; April 6. doi:10.1001/ jama.2020.5394

11. Alhazzani W, Møller MH, Arabi YM, et al. Surviving sepsis campaign: guidelines on the management of critically ill adults with coronavirus disease 2019 (COVID-19). Intensive Care Med 2020; Mar 28. doi:10.1007/s00134-020-06022-5

12. Ebert TJ. Sympathetic and hemodynamic effects of moderate and deep sedation with propofol in humans. Anesthesiology 2005; 103(1):20-24. doi:10.1097/00000542-200507000-00007

13. Guo T, Fan Y, Chen M, et al. Cardiovascular implications of fatal outcomes of patients with coronavirus disease 2019 (COVID-19). JAMA Cardiol 2020; Mar 27. doi:10.1001/jamacardio.2020.1017

14. Madjid M, Safavi-Naeini P, Solomon SD, Vardeny O. Potential effects of coronaviruses on the cardiovascular system: a review. JAMA Cardiol 2020; Mar 27. doi:10.1001/jamacardio.2020.1286

15. Cecconi M, De Backer D, Antonelli M, et al. Consensus on circulatory shock and hemodynamic monitoring. Task Force of the European Society of Intensive Care Medicine. Intensive Care Med 2014; 40(12):1795-1815. doi:10.1007/s00134-014-3525-z

16. Zochios V, Parhar K, Tunnicliffe W, Roscoe A, Gao F. The right ventricle in ARDS. Chest 2017; 152(1):181-193. doi:10.1016/j. chest.2017.02.019

17. Vignon P, Repessé X, Bégot $\mathbf{E}$, et al. Comparison of echocardiographic indices used to predict fluid responsiveness in ventilated patients. Am J Respir Crit Care Med 2017; 195(8):1022-1032. doi:10.1164/rccm.201604-08440C

18. Vignon P, AitHssain A, François B, et al. Echocardiographic assessment of pulmonary artery occlusion pressure in ventilated patients: a transoesophageal study. Crit Care 2008; 12(1):R18. doi:10.1186/ cc6792

19. Cui S, Chen S, Li X, Liu S, Wang F. Prevalence of venous thromboembolism in patients with severe novel coronavirus pneumonia [published online ahead of print April 9, 2020]. J Thromb Haemost. doi: $10.1111 /$ jth.14830

20. Tang N, Bai H, Chen X, Gong J, Li D, Sun Z. Anticoagulant treatment is associated with decreased mortality in severe coronavirus disease 2019 patients with coagulopathy. J Thromb Haemost 2020; Mar 27. doi: $10.1111 /$ jth. 14817

21. Kory PD, Pellecchia CM, Shiloh AL, Mayo PH, DiBello C, Koenig S. Accuracy of ultrasonography performed by critical care physicians for the diagnosis of DVT. Chest 2011; 139(3):538-542. doi:10.1378/ chest.10-1479

22. Pomero F, Dentali F, Borretta V, et al. Accuracy of emergency physician-performed ultrasonography in the diagnosis of deep-vein thrombosis: a systematic review and meta-analysis. Thromb Haemost 2013; 109(1):137-145. doi:10.1160/TH12-07-0473

23. Frankel HL, Kirkpatrick AW, Elbarbary M, et al. Guidelines for the appropriate use of bedside general and cardiac ultrasonography in the evaluation of critically ill patients-Part I: general ultrasonography. Crit Care Med 2015; 43(11):2479-2502. doi:10.1097/ CCM.0000000000001216

24. Needleman L, Cronan JJ, Lilly MP, et al. Ultrasound for lower 
extremity deep venous thrombosis: multidisciplinary recommendations from the Society of Radiologists in Ultrasound Consensus Conference. Circulation 2018; 137(14):1505-1515. doi:10.1161/ CIRCULATIONAHA.117.030687

25. Franco-Sadud R, Schnobrich D, Mathews BK, et al; SHM Point-ofcare Ultrasound Task Force. Recommendations on the use of ultrasound guidance for central and peripheral vascular access in adults: a position statement of the Society of Hospital Medicine. J Hosp Med 2019; 14:E1-E22. doi:10.12788/jhm.3287
26. American College of Emergency Physicians. ACEP Guideline on COVID-19: Ultrasound Machine and Transducer Cleaning. https:// www.acep.org/globalassets/new-pdfs/guideline-on-covid-19--ultrasound-machine-and-transducer-cleaning_policy_033120.pdf. Accessed April 16, 2020.

27. Centers for Disease Control and Prevention. Cleaning and disinfection for community facilities. https://www.cdc.gov/ coronavirus/2019-ncov/community/organizations/cleaning-disinfection.html. Accessed April 16, 2020.

\section{APPENDIX. RESOURCES FOR FURTHER LEARNING}

\section{Learning Modules}

Cleveland Clinic MyLearning

mylearning.ccf.org/login/index.php

Ultrasound Leadership Academy

ultrasoundleadershipacademy.com/academy/\#/bt_section5e78dfc6d9af6

\section{Podcasts}

Core Ultrasound

www.coreultrasound.com/usp_covid_1

Ultrasound GEL

https://www.ultrasoundgel.org/posts/bcLLYxfR8yN1SmYvwXPW9A

WINFOCUS

www.winfocus.org/covid-19/covid-19-infection-diagnosis-monitoring-and-prognosis-is-it-possible 